\title{
Supplement to: Intraseasonal to interannual variability of Kelvin wave momentum fluxes as derived from high-resolution radiosonde data
}

Jeremiah P. Sjoberg ${ }^{1,2}$, Thomas Birner ${ }^{1}$, and Richard H. Johnson ${ }^{1}$

${ }^{1}$ Department of Atmospheric Science, Colorado State University, Fort Collins, CO 80521

${ }^{2}$ now at: COSMIC Project Office, University Corporation for Atmospheric Research, Boulder, Colorado

Correspondence to: Jeremiah P. Sjoberg (sjoberg@ucar.edu) 

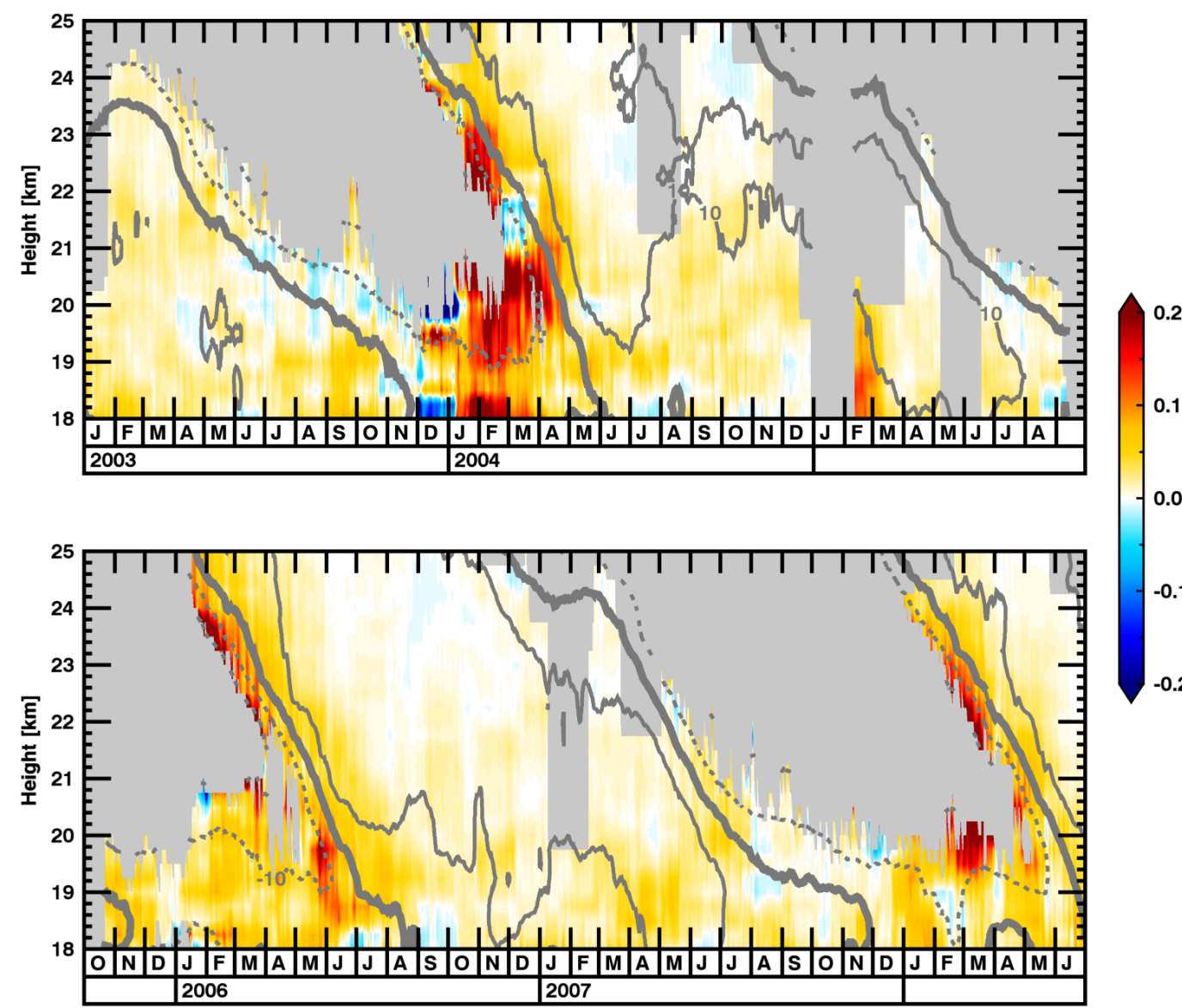

Figure S1. Time series of momentum fluxes from the Nauru ARM site. The span here covers 01 January 2003 through 30 June 2008 . The dark gray contours give the estimated zonal mean zonal wind at each site; solid contours are westerlies while dashed contours are easterlies. Gray shading indicates where the momentum flux is not being calculated for any frequency band. Momentum flux is in units of mPa and zonal wind contour spacing (gray contours) is $10 \mathrm{~m} \mathrm{~s}^{-1}$. 


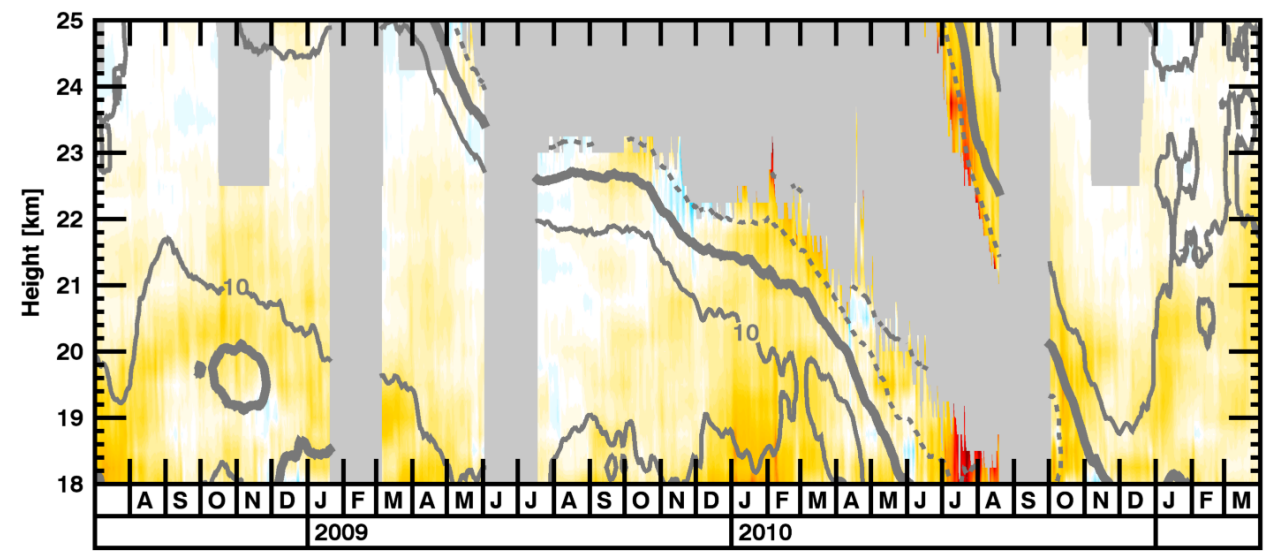

0.2

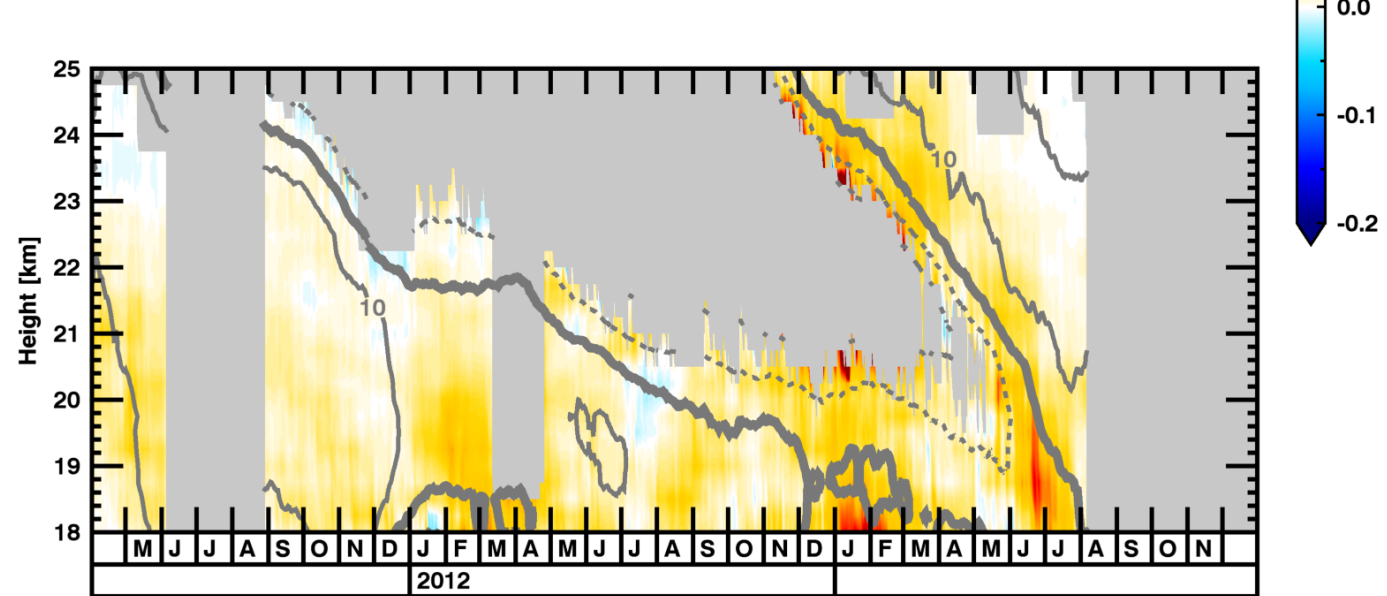

Figure S2. Time series of momentum fluxes from the Nauru ARM site, continued. The span here covers 01 July 2008 through 31 December 2013. 